\title{
The impact of a cardiovascular health awareness program (CHAP) on reducing blood pressure: a prospective cohort study
}

\author{
Chenglin Ye ${ }^{1,2}$, Gary Foster ${ }^{1,2}$, Janusz Kaczorowski, ${ }^{3,4}$, Larry W Chambers ${ }^{1,5,6,7}$, Ricardo Angeles ${ }^{3}$, \\ Francine Marzanek-Lefebvre ${ }^{3}$, Stephanie Laryea ${ }^{8}$, Lehana Thabane ${ }^{1,2}$ and Lisa Dolovich, ${ }^{1,3^{*}}$
}

\begin{abstract}
Background: Hypertension is an important and modifiable cardiovascular risk factor that remains under-detected and under-treated, especially in the older individuals. Community-led interventions that integrate primary health care and local resources are promising approaches to improve awareness and management of hypertension and other cardiovascular risk factors. We aimed to evaluate the effect of a community-based Cardiovascular Health Awareness Program (CHAP) on participants' blood pressure.
\end{abstract}

Methods: This study followed a cohort of community residents that participated in CHAP across 22 mid-sized Ontario communities over an 18-month period. The participants' baseline risk factors, including blood pressure, and subsequent measures of blood pressure were recorded. We employed a bivariate linear mixed-effect model to estimate the change of systolic and diastolic blood pressure over time among the participants who attended more than two CHAP sessions.

Results: Of 13,596 participants, 2498 attended more than two CHAP sessions. For those repeated participants (attending more than two sessions) initially identified with high blood pressure, the average reduction of systolic blood pressure was from 142 to $123 \mathrm{mmHg}$ over an 18-month period, a monthly rate ratio of 0.992 ( $95 \% \mathrm{Cl}: 0.991,0.994 ; \mathrm{p}<0.01$ ). Similarly, the average reduction of diastolic blood pressure was from 78 to $69 \mathrm{mmHg}$, a monthly rate ratio of 0.993 (95\% Cl: $0.991,0.994 ; p<0.01)$. The average blood pressure of the participants with normal baseline blood pressure remained controlled and unchanged. We also found that older adult participants who lived alone, were diagnosed with hypertension, reported healthier eating habits, and presented with a higher baseline systolic blood pressure had significantly greater odds of attending more than one session.

Conclusions: CHAP was associated with a reduction in systolic and diastolic blood pressure for those participants who attended more than one session. The magnitude of blood pressure reductions was significant clinically and statistically.

\section{Background}

Cardiovascular disease (CVD), including heart failure, ischemic heart disease, and stroke, are the most common causes of death in Canada [1]. Treatment of CVD accounts for the largest proportion of Canadian health care expenditures $[1,2]$. It is estimated that the majority of CVD can be prevented through managing preventable and modifiable risk factors. One readily preventable risk

\footnotetext{
* Correspondence: Idolovic@mcmaster.ca

'Department of Clinical Epidemiology and Biostatistics, McMaster University, Hamilton, ON, Canada

${ }^{3}$ Department of Family Medicine, McMaster University, McMaster Innovation Park, 175 Longwood Road South, Hamilton, ON L8P OA1, Canada Full list of author information is available at the end of the article
}

factor of CVD is high blood pressure, also known as hypertension. Hypertension is among the top leading causes of death in the world [3]. In Canada, the prevalence of hypertension has remained relatively constant at around $20 \%$ of adult population over the last 3 decades (1985-2011). However, both the prevalence and incidence of hypertension increases with age. Approximately $40 \%$ of Canadians have hypertension by the age of 55 years [4-6]. For those who do not have hypertension by the age of 55 years, the residual lifetime risk of developing it is $90 \%$ [7].

Hypertension is generally asymptomatic. About $18 \%$ of adults with hypertension are unaware of their condition [8]. Another $18 \%$ of adults diagnosed with hypertension

\section{Biomed Central}

(c) 2013 Ye et al.; licensee BioMed Central Ltd. This is an open access article distributed under the terms of the Creative Commons Attribution License (http://creativecommons.org/licenses/by/2.0), which permits unrestricted use, distribution, and reproduction in any medium, provided the original work is properly cited. 
are not treated or controlled, leaving only about $64 \%$ of Canadians with adequately controlled hypertension [8]. The main barriers to optimal diagnosis, treatment and control include 'white coat effect' [9], 'masked hypertension' [10], co-morbidities [11,12], and non-adherence to both pharmacological treatments and lifestyle recommendations [13-17]. Both lifestyle and pharmacological treatments have been shown to be effective at reducing blood pressure (BP) and associated cardiovascular risk factors. Improving $\mathrm{BP}$ control is one of the most costeffective health care interventions available [18]. A 10\% decrease in the prevalence of hypertension would save more than $\$ 430$ million per year in Canada [19]. More importantly, it would have a major impact on reducing cardiovascular morbidity and mortality.

Research suggests that community interventions that have included BP monitoring in a non-clinical setting and utilized community resources show promising results on reducing and controlling $\mathrm{BP}$ among hypertensive patients [19-22]. Community resources such as volunteers, pharmacists, health nurses, and local organizations are underutilized to support disease prevention and primary health care in Canada. Synergy created by connecting family physicians, pharmacists, patients, peer volunteers and local resources can lead to better health outcomes for community residents [23].

\section{Cardiovascular health awareness program (CHAP)}

The Cardiovascular Health Awareness Program (CHAP) is a community-led approach that targets cardiovascular awareness and prevention for the older adults by providing risk assessment, repeated measurement of BP, education materials, lifestyle recommendations, and access to community resources. The program integrates primary care and local resources through the collaboration of family physicians, pharmacists, local organizations, and trained volunteer peer health educators [24]. Participation in CHAP is free and open to all residents of participating communities but individuals aged 65 years or older are explicitly targeted. Potential participants are invited by their family physicians to attend CHAP sessions held in local pharmacies. Other invitation strategies include flyers, posters, and local media campaigns through radio. The trained volunteer peer health educators, with support from a community nurse and a local program coordinator, lead CHAP sessions. In those sessions, peer health educators assist participants to measure their BP using an accurate automated device (BpTRU) and complete a CVD risk profile. Based on the risk profiles, participants may be advised to attend another session for re-assessment and follow up with their family physician [24]. The action-oriented summaries of up-to-date BP and CVD risk information are sent back to family physicians and pharmacists via an automated data system.

CHAP was developed and refined through several pilot studies and community-wide demonstrations [24-27]. It was most recently assessed in a randomized controlled trial that randomly allocated 20 mid-sized communities across Ontario, Canada to run CHAP compared with 19 control communities [22]. The result showed that CHAP communities had a significant annual reduction of $9 \%$ in cardiovascular hospital admissions in comparison with non-CHAP communities (rate ratio 0.91, 95\% confidence interval 0.86 to $0.97 ; \mathrm{p}=0.002$ ). After these promising results, CHAP continued to be implemented in 22 mid-sized communities across Ontario. The on-going goal is to develop CHAP as a sustainable communityowned program, with the aim of localizing community resources to ultimately achieve improved long-term health outcomes. CHAP is continuously evaluated by routinely collected data from the 22 communities. This is a unique data set from a real-world program that was able to follow participants for a number of months. The on-going implementation and evaluation of CHAP is an important step forward for community-led cardiovascular prevention programs which, up till now, have produced largely disappointing effects on clinical outcomes [11-13,28,29]. Today, 9 communities in Ontario have successfully adopted CHAP as their regular community program. A CHAP implementation guide targeting community end-users has been built to provide a 'road map' for new communities who are interested in implementing CHAP (www.chapprogram.ca). Part of current work on CHAP focuses on understanding the longitudinal effect of $\mathrm{CHAP}$ on reducing $\mathrm{BP}$ among hypertensive patients and the characteristics associated with participants' participation in the program. The analyses are mainly to inform further operations of CHAP about an array of features of the program that arises in real-world implementation of the program.

In this paper, our objectives are to estimate the changes of participants' BP over subsequent visits and examine what factors were associated with individuals' continuous participation in CHAP.

\section{Methods}

\section{Ethics statement}

The participation in CHAP sessions was voluntary and did not require participants' consent. However, blood pressure readings and other information on cardiovascular risk factors were collected and sent back to their family physician and regular pharmacist with participants' written consent. The study and the consent procedure were approved by the research ethics boards at Bruyère Continuing Care in Ottawa, Sunnybrook Health 
Sciences Centre in Toronto, and McMaster University in Hamilton, Canada.

\section{Study design}

This longitudinal cohort study followed the participants who attended CHAP sessions between May 2008 and April 2010. These CHAP sessions were delivered weekly in 22 communities after the completion of the RCT. Although those sessions were run independently of the main study, they were organized in the same way. Physician referral and local advertisements were the primary means of inviting participants. In those CHAP sessions, trained volunteer peer health educators assisted participants to take BP measurements with the BpTRU device and recorded self-reported CVD risk factors on the standardized risk profile form. An on-site community nurse was available to assess participants who had abnormal $\mathrm{BP}$ and trained volunteer peer health educators referred eligible participants to community pharmacists for a medication assessment. The medication assessment was a one-to-one meeting to ensure the safe and appropriate use of all types of medication. The CVD risk factors collected at baseline included the participants' age, gender, body mass index (BMI), systolic blood pressure (SBP), diastolic blood pressure (DBP), history on transient ischemic attack (TIA), stroke, heart attack, high cholesterol and high BP, smoking status, drinking habits, eating habits (the consumption of high fat foods, vegetables, fruit and salt), stress level, physical exercises, and whether they lived alone or not. A detailed protocol of CHAP intervention can be found here [30]. The clinical outcomes of interest were SBP and DBP. Participants' SBP and DBP were recorded during repeated CHAP sessions using standardized protocols, assistance from peer health educator volunteers, and validated automated BP devices. In keeping with the BpTRU protocol, during the first visit and subsequent visits, the BpTRU automated blood pressure measuring device independently assessed the blood pressure with volunteer peer health educators assisting with the cuff size, if required, and assisting with recording the blood pressure taken on the data collection form. The first reading was automatically discarded and the volunteer recorded the mean value of the five subsequent measurements produced by the BPTRU on the participant's form. In CHAP, the BpTRU is set to have a one-minute interval between readings. A typical period of time required at a session was 20 minutes.

There are two considerations for the analysis of the repeated BP measurements. First, the number of total BP measurements was generally different among participants. Second, the time interval between consecutive measurements also varied. This was due to CHAP being a volunteer self-directed program that allowed participants to attend as many sessions as they wished. The number of participants also decreased over time (Figure 1). These unequally spaced BP observations created challenges in the analysis because the time interval between consecutive measures is not the same for all participants.

\section{Statistical analysis}

Participants were divided into three groups for the analysis: participants who attended only one session, two sessions, or more than two sessions (Figure 2). Mean (standard deviation) and number of count (percentage) were calculated for the continuous variables and categorical variables, respectively. The literature on longitudinal analysis suggests a minimum of at least three consecutive measures to model change through time [31]. Thus, for estimating the longitudinal effect of $\mathrm{CHAP}$ on reducing $\mathrm{BP}$, only participants with more than two visits were included in the analysis.

A bivariate linear mixed-effect model [32-34] was used to fit SBP and DBP simultaneously by taking into account the correlation between both measures. The time of measurement was used as a continuous variable. That way, we could relate the SBP and DBP measurements to the individual time of observation to address the problem of unequally spacing between visits [35-38]. A continuous autoregressive (CAR) structure was specified for modeling the within-subject variance of the BP measurements. The CAR structure treated time between sessions as a continuous variable and allowed time-dependent correlation between measurements, e.g. the correlation between BP measurements got smaller when they were further apart. The details of the model are provided in the Additional file 1.

A logarithm transformation was applied to the outcomes to adjust for non-linear reduction over time. The SBP and DBP dropped more quickly at earlier sessions and then the reduction became smaller and smaller. In the model, we included a baseline binary variable to indicate whether the participants initially had high BP or not. According to the Canadian hypertension education program recommendations [39], the cut-off defining high SBP/DBP is $\geq 140 / 90 \mathrm{mmHg}$ for individuals without diabetes and $\geq 130 / 80$ for individuals with diabetes. The participants were classified in the high BP group at baseline if either SBP or DBP was above the threshold. An interaction term between the BP level indicator and the time variable was also included to allow the rate of $\mathrm{BP}$ change to vary between participants of different levels of initial BP.

A second analysis was conducted to examine the factors that were associated with participation in CHAP. Two logistic regression models were fitted on all participants for the odds of ever returning for another session and the odds for a new participant to be advised for the second session, respectively. The overall rate of missing 


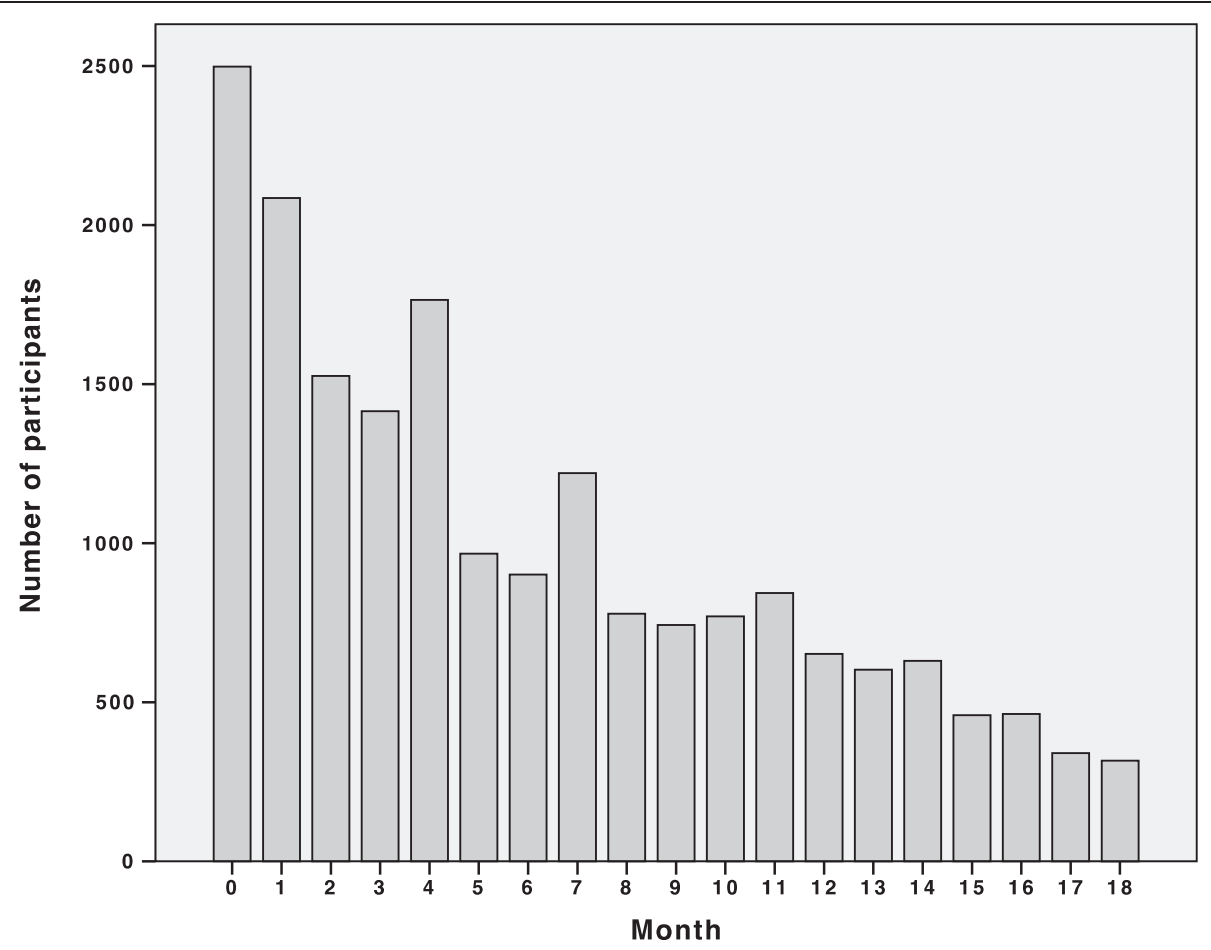

Figure 1 Distribution of the number of participants over time (more than two visits). This figure shows the distribution of the number of CHAP participants who attended more than two sessions by month. The number of participants generally decreases over time. There are more participants in some months than in previous months because CHAP being a volunteer self-directed program allows participants to attend any session.

observations for all variables was less than $14 \%$. We assumed any missing observation to be missing at random (MAR) and used the multiple imputation (MI) technique to generate those missing values by baseline factors. The Monte Carlo Markov Chain (MCMC) method was used to simulate the sampling distribution for 10 imputation draws. We reported the estimate of BP change in rate ratio (RR), corresponding 95\% confidence interval (CI) and $\mathrm{p}$ value. We chose the alpha to be $5 \%$. All statistical analyses were performed in SAS 9.2 (SAS Institute, Cary NC).

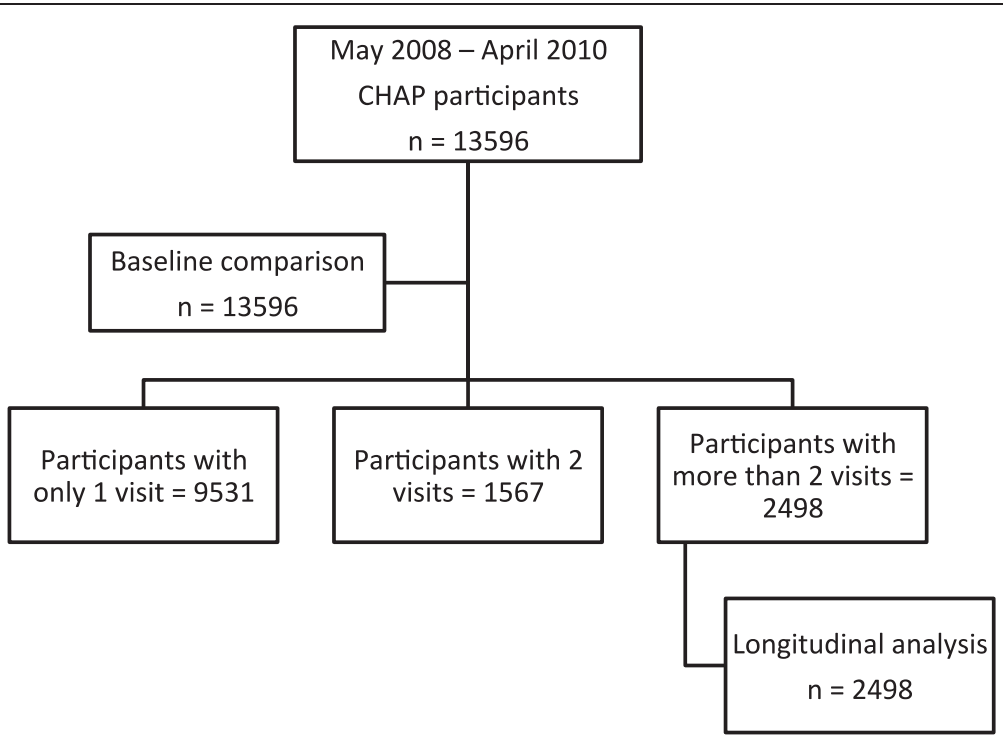

Figure 2 Flowchart of the study participants. This flowchart divides the number participants by the number of sessions: one session, two sessions or more than two sessions. It shows the number of participants for baseline comparison and the longitudinal analysis. 


\section{Results}

CHAP sessions processed 13,596 participants between May 2008 and April 2010: 70\% (9,531 of 13,596) attended only one session; $12 \%(1,567$ of 13,596$)$ attended two sessions; and $18 \%(2,498$ of 13,596$)$ attended more than two sessions. The baseline variables are summarized in Tables 1 and 2. The average SBP, DBP, and BMI scores on all participants were $128 \mathrm{mmHg}, 74 \mathrm{mmHg}$, and $28 \mathrm{~kg} / \mathrm{m}^{2}$, respectively and were similar across the subgroups. The average age was 67 years old and was higher among the participants who attended more than one session. Overall, $8.9 \%(1,101$ of 12,304$)$ participants reported a previous heart attack; $41.1 \%(5,048$ of 12,288$)$ reported high cholesterol; $16.0 \%(1,968$ of 12,299$)$ reported diabetes; and $54.0 \%$ $(6,636$ of 12,280$)$ reported hypertension. The participants who attended multiple sessions reported more cardiovascular disease histories. The participants who attended more than one session reported a healthier lifestyle than those who attended only one session, e.g. less smoking, alcohol, high fat food, salt and stress, and more fruit, vegetables and physical activity. Also, the participants who lived by themselves were more likely to attend more sessions.

In Table 3, we summarize the results for estimating the $\mathrm{BP}$ change over repeated visits. The rate ratio (RR) estimate of $\mathrm{BP}$ change was interpreted as the percentage of $\mathrm{BP}$ change each month. For the participants initially identified with high BP, the RR of SBP and DBP was 0.9921 (95\% CI: 0.9905,0.9937; p < 0.01) and 0.9929 (95\% CI: $0.9914,0.9944 ; \mathrm{p}<0.01)$, respectively. These results showed that on average the SBP and DBP dropped 0.79\% and $0.71 \%$, respectively every month in CHAP. In contrast, the RR of SBP and DBP for the participants without high BP was 0.9999 (95\% CI: 0.9993,1.0004; p = 0.69) and 0.9996 (95\% CI: 0.9990,1.0001; p $=0.11$ ), respectively. That represented an average drop of $0.01 \%$ and $0.04 \%$ on SBP and DBP, respectively every month. In summary, the average SBP/DBP for the high BP group was reduced from $142 / 78 \mathrm{mmHg}$ to $123 / 69 \mathrm{mmHg}$ over an 18 -month period; and remained unchanged for the non-high BP

Table 1 Summary of baseline categorical risk factors

\begin{tabular}{|c|c|c|c|c|c|c|c|c|c|}
\hline \multirow[t]{2}{*}{ Risk factors } & & \multicolumn{2}{|c|}{$\begin{array}{l}\text { All participants } \\
(n=13596)\end{array}$} & \multicolumn{2}{|c|}{$\begin{array}{l}\text { Participants with } \\
\text { only } 1 \text { visit } \\
\text { (n=9531) }\end{array}$} & \multicolumn{2}{|c|}{$\begin{array}{l}\text { Participants } \\
\text { with } 2 \text { visits } \\
\text { ( } n=1567)\end{array}$} & \multicolumn{2}{|c|}{$\begin{array}{l}\text { Participants with } \\
\text { more than } 2 \\
\text { visits }(n=2498)\end{array}$} \\
\hline & & Count & Percentage & Count & Percentage & Count & $\overline{\text { Percentage }}$ & Count & Percentage \\
\hline Gender & Male & 4987 & $36.7 \%$ & 3525 & $37.2 \%$ & 580 & $37.0 \%$ & 865 & $34.6 \%$ \\
\hline Age & $\geq 65$ years old & 8495 & $62.5 \%$ & 5432 & $57.0 \%$ & 1119 & $71.5 \%$ & 1944 & $77.8 \%$ \\
\hline BP level & High & 3975 & $29.3 \%$ & 2744 & $28.8 \%$ & 429 & $27.4 \%$ & 802 & $32.2 \%$ \\
\hline Previous TIA? & Yes & 893 & $7.3 \%$ & 581 & $6.7 \%$ & 106 & $7.6 \%$ & 198 & $8.9 \%$ \\
\hline Previous stroke? & Yes & 370 & $3.0 \%$ & 239 & $2.8 \%$ & 42 & $3.0 \%$ & 85 & $3.8 \%$ \\
\hline Previous heart attack? & Yes & 1101 & $8.9 \%$ & 750 & $8.7 \%$ & 139 & $10.0 \%$ & 208 & $9.4 \%$ \\
\hline High cholesterol? & Yes & 5048 & $41.1 \%$ & 3433 & $39.8 \%$ & 608 & $43.6 \%$ & 976 & $44.2 \%$ \\
\hline Diabetes? & Yes & 1968 & $16.0 \%$ & 1349 & $15.6 \%$ & 216 & $15.5 \%$ & 397 & $18.0 \%$ \\
\hline Hypertension? & Yes & 6636 & $54.0 \%$ & 4377 & $50.8 \%$ & 819 & $58.8 \%$ & 1408 & $63.7 \%$ \\
\hline Currently smoking? & Yes & 1424 & $11.6 \%$ & 1115 & $12.9 \%$ & 132 & $9.5 \%$ & 172 & $7.8 \%$ \\
\hline \multirow{3}{*}{$\begin{array}{l}\text { How many times eating high fat } \\
\text { food weekly? }\end{array}$} & 3 or more & 1247 & $10.1 \%$ & 922 & $10.7 \%$ & 124 & $8.9 \%$ & 196 & $8.8 \%$ \\
\hline & $1-2$ times & 7099 & $57.7 \%$ & 4996 & $57.9 \%$ & 819 & $58.8 \%$ & 1252 & $56.5 \%$ \\
\hline & Zero & 3953 & $32.1 \%$ & 2717 & $31.5 \%$ & 451 & $32.4 \%$ & 768 & $34.7 \%$ \\
\hline $2+$ alcoholic drinks daily? & Yes & 1003 & $8.2 \%$ & 734 & $8.5 \%$ & 110 & $7.9 \%$ & 157 & $7.1 \%$ \\
\hline $5+$ servings of fruit and vegetable? & Yes & 7482 & $61.2 \%$ & 5126 & $59.8 \%$ & 855 & $61.7 \%$ & 1463 & $66.5 \%$ \\
\hline \multirow[t]{3}{*}{ Adding salt to food? } & Often & 1693 & $13.8 \%$ & 1278 & $14.9 \%$ & 165 & $11.9 \%$ & 237 & $10.7 \%$ \\
\hline & Sometimes & 3059 & $25.0 \%$ & 2140 & $24.9 \%$ & 351 & $25.3 \%$ & 554 & $25.1 \%$ \\
\hline & Rarely & 7476 & $61.1 \%$ & 5160 & $60.2 \%$ & 874 & $62.9 \%$ & 1415 & $64.1 \%$ \\
\hline \multirow[t]{3}{*}{ Feeling stressed? } & Often & 2033 & $16.6 \%$ & 1513 & $17.6 \%$ & 217 & $15.7 \%$ & 292 & $13.2 \%$ \\
\hline & Sometimes & 4553 & $37.2 \%$ & 3210 & $37.4 \%$ & 503 & $36.3 \%$ & 821 & $37.3 \%$ \\
\hline & Rarely & 5645 & $46.2 \%$ & 3865 & $45.0 \%$ & 665 & $48.0 \%$ & 1091 & $49.5 \%$ \\
\hline Daily exercise? & Yes & 9563 & $77.7 \%$ & 6701 & $77.5 \%$ & 1087 & $77.8 \%$ & 1732 & $78.1 \%$ \\
\hline Live alone? & Yes & 3615 & $29.4 \%$ & 2328 & $27.0 \%$ & 456 & $32.6 \%$ & 1398 & $36.8 \%$ \\
\hline
\end{tabular}

$\mathrm{BP}=$ blood pressure; $\mathrm{TIA}=$ transient ischemic attack. 
Table 2 Summary of baseline continuous risk factors

\begin{tabular}{|c|c|c|c|c|c|c|c|c|}
\hline \multirow[t]{2}{*}{ Risk factors } & \multicolumn{2}{|c|}{ All participants $(n=13596)$} & \multicolumn{2}{|c|}{$\begin{array}{l}\text { Participants with only } 1 \text { visit } \\
(n=9531)\end{array}$} & \multicolumn{2}{|c|}{$\begin{array}{l}\text { Participants with } 2 \text { visits } \\
(n=1567)\end{array}$} & \multicolumn{2}{|c|}{$\begin{array}{l}\text { Participants with more than } 2 \text { visits } \\
(\mathrm{n}=2498)\end{array}$} \\
\hline & Mean & SD & Mean & SD & Mean & SD & Mean & SD \\
\hline $\mathrm{SBP}(\mathrm{mmHg})$ & 128.0 & 19.1 & 127.3 & 19.1 & 128.2 & 18.6 & 129.9 & 19.0 \\
\hline $\mathrm{DBP}(\mathrm{mmHg})$ & 74.3 & 11.2 & 74.7 & 11.1 & 72.9 & 11.0 & 73.1 & 11.0 \\
\hline Age (year) & 67.1 & 13.5 & 65.4 & 14.1 & 70.1 & 12.0 & 71.7 & 10.5 \\
\hline BMI $\left(\mathrm{kg} / \mathrm{m}^{2}\right)$ & 27.9 & 5.4 & 28.0 & 5.4 & 27.7 & 5.4 & 27.7 & 5.3 \\
\hline
\end{tabular}

$\mathrm{SD}=$ standard deviation; $\mathrm{SBP}=$ systolic blood pressure; $\mathrm{DBP}=$ diastolic blood pressure; $\mathrm{BMI}=$ body mass index .

group. For the participants who showed high BP at baseline, the ones who reported diabetes on average had 2.5 and $3.3 \mathrm{mmHg}$ more reduction in SBP and DBP, respectively, than those who did not. In contrast, for the participants who did not show high BP at baseline, the ones who reported diabetes on average had 2.9 and $3.0 \mathrm{mmHg}$ more reduction in SBP and DBP, respectively, than those who did not. Figures 3 and 4 illustrate the trend of $\mathrm{BP}$ reduction over time. We have examined the multi-collinearity among the baseline risk factors by calculating their variance inflation factor (VIF) and did not find any strong multi-collinearity, i.e. $\mathrm{VIF}<10$.

The 22 mid-sized communities in this study are similar in their demographic profile, e.g. population composition, income, and residents' education level. The distribution of BP for CHAP participants in each community is also similar but the number of total population varies. To explore the community effect on the BP change, we fitted a mixed-effect model by incorporating an additional community factor in the hierarchical structure (i.e. visit, participant and community levels). The estimated rates of BP change were similar to those obtained previously. However, the 3-level model resulted in a non-positive Hessian matrix, suggesting unstable estimates and potential over-specification of the model [40]. Thus, we report the mixed-effect model without the community factor since it provides stable estimates with a simpler covariance structure.
In Table 4, we summarize the results from the logistics regression analyses examining the factors associated with participation in CHAP. The odds of attending multiple sessions were increased by 3\% (OR 1.03, 95\% CI: 1.03$1.04 ; \mathrm{p}<0.01)$ for every year increase in age. The participants who were diagnosed with hypertension, ate more than five servings of fruit and vegetables daily, rarely added salt to food, and lived alone had 30\% (OR 1.30, 95\% CI: $1.19-1.42$; $\mathrm{p}=0.01$ ), 14\% (OR 1.14, 95\% CI: 1.04$1.24 ; \mathrm{p}=0.01), 18 \%$ (OR 1.18, 95\% CI: 1.03-1.34; $\mathrm{p}=$ 0.02 ) and $17 \%$ (OR 1.17, 95\% CI: 1.06-1.28; p < 0.01) higher odds of attending more than one session than those who did not, respectively. Also, the new participants who often felt stressed were associated with 19\% higher odds of being advised to attend the second session.

\section{Discussion}

In this study, BP of CHAP participants initially identified with high BP significantly dropped over time. An average reduction of $20 / 10 \mathrm{mmHg}$ in SBP/DBP occurred over 18 months. Such a reduction in BP greatly lowers the risk of developing cardiovascular disease. A decrease of $\mathrm{SBP} / \mathrm{DBP}$ by $10 / 5 \mathrm{mmHg}$ reduces the risk of developing heart failure by about $50 \%$, stroke by $38 \%$, heart attack by $15 \%$, and death by $10 \%$ [41]. At the same time, the participants without high BP at baseline were also well controlled in terms of their follow-up BP. These findings support our hypothesis that the use of community

Table 3 Summary of results from the bivariate linear mixed-effect model

\begin{tabular}{|c|c|c|c|c|c|c|c|c|}
\hline & \multicolumn{4}{|c|}{ Systolic blood pressure } & \multicolumn{4}{|c|}{ Diastolic blood pressure } \\
\hline & $\mathbf{R R}^{*}$ & & $95 \% \mathrm{Cl}$ & $p$ value & $\mathbf{R R}^{*}$ & & & $p$ value \\
\hline \multicolumn{9}{|c|}{ High blood pressure at baseline } \\
\hline Baseline & 141.61 & (138.56 & 144.74) & $<0.01$ & 78.13 & $(75.99$ & $80.32)$ & $<0.01$ \\
\hline Rate ratio & 0.9921 & $(0.9905$ & $0.9937)$ & $<0.01$ & 0.9929 & $(0.9914$ & $0.9944)$ & $<0.01$ \\
\hline \multicolumn{9}{|c|}{ Not high blood pressure at baseline } \\
\hline Baseline & 120.44 & $(118.79$ & 122.12) & $<0.01$ & 69.93 & $(68.67$ & 71.21) & $<0.01$ \\
\hline Rate ratio & 0.9999 & (0.9993 & 1.0004) & 0.69 & 0.9996 & (0.9990 & $1.0001)$ & 0.11 \\
\hline
\end{tabular}

$\mathrm{RR}=$ rate ratio; $\mathrm{Cl}=$ confidence interval.

Rate ratio was expressed as the change of current blood pressure in 1 month

*The rate ratio was adjusted for all baseline risk factors. 


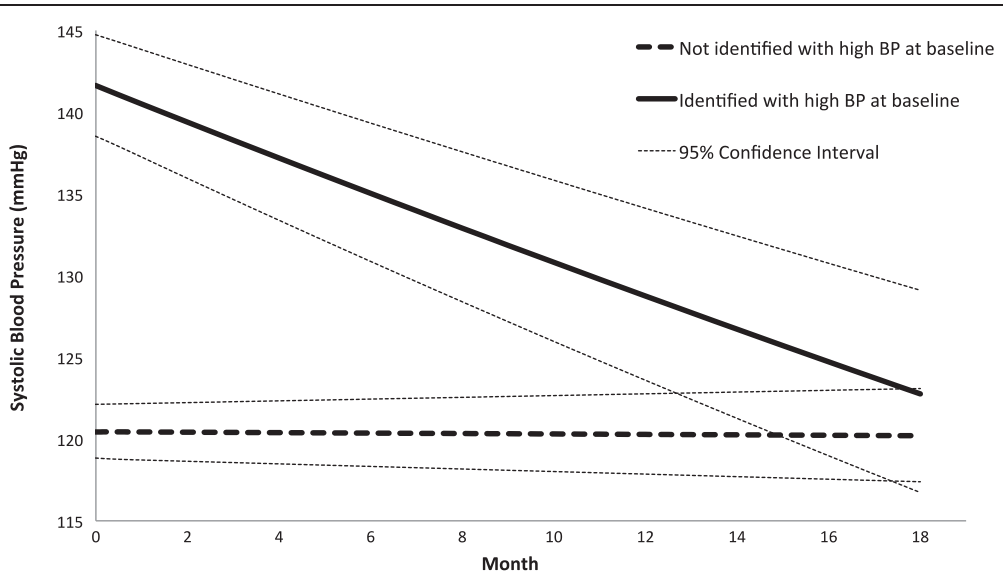

Figure 3 Reduction of systolic blood pressure over time. This figure shows the reduction of systolic blood pressure for the participants who attended more than two sessions. The reduction is presented separately for those who presented with high blood pressure at baseline (without diabetes: systolic blood pressure $\geq 140$ or diastolic blood pressure $\geq 90$; with diabetes: systolic blood pressure $\geq 130$ or diastolic blood pressure $\geq 80$ ) and for those who did not.

pharmacies and peer health educators to enhance care received at the family physician's office overcome traditional barriers associated with measuring, treating, and controlling BP at a doctor's office [23,24].

When compared with the participants who attended only one session, we found that the participants who attended multiple sessions generally presented with higher baseline cardiovascular risk and a healthier lifestyle. Participants who lived by themselves were more likely to come back for more CHAP sessions. From the logistic regression analysis, we found that older adult participants who lived alone, were diagnosed with hypertension previously, had healthier eating habits, and presented with higher baseline SBP had a greater likelihood of attending more than one CHAP session. In addition, for those participants who often felt stressed, they were much likely to be recommended to come back for re-assessment.

Our study was limited by a number of factors. First, risk factors were only recorded at baseline and, apart from BP, were self-reported. This prevented us from accounting for the change of risk factors over time. Second, by the pragmatic nature of the study, we cannot know which specific components of CHAP were working to reduce BP for the participants. For example, the $\mathrm{BP}$ reduction could be a result of an improved detection and treatment of hypertension, improved adherence to lifestyle changes or pharmacological treatments, more frequent follow-ups by family physicians initiated by CHAP for cardiovascular disease prevention, or greater efforts by integrating local resources to promote cardiovascular

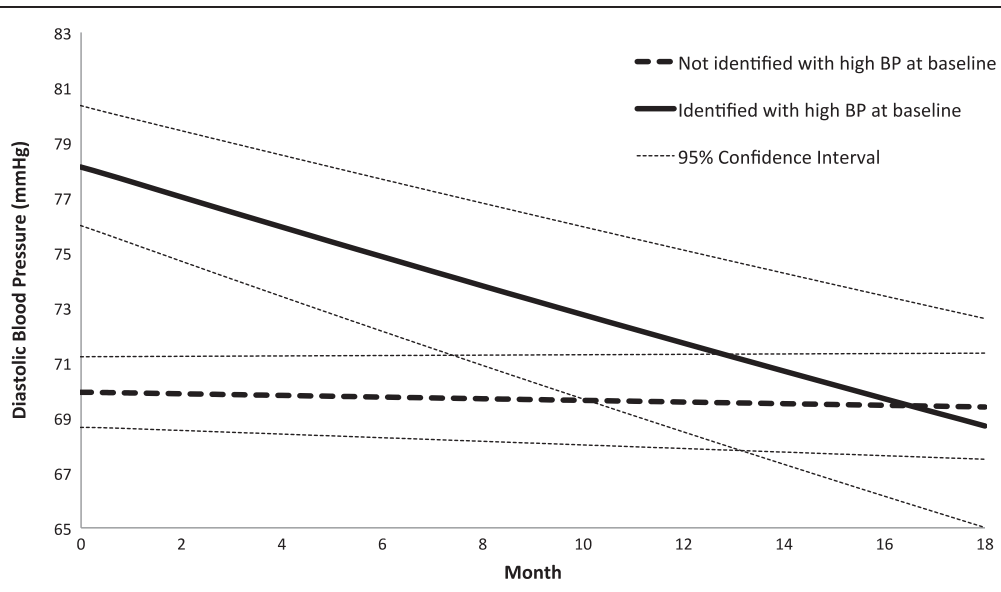

Figure 4 Reduction of diastolic blood pressure over time. This figure shows the reduction of diastolic blood pressure for the participants who attended more than two sessions. The reduction is presented separately for those who presented with high blood pressure at baseline (without diabetes: systolic blood pressure $\geq 140$ or diastolic blood pressure $\geq 90$; with diabetes: systolic blood pressure $\geq 130$ or diastolic blood pressure $\geq 80$ ) and for those who did not. 
Table 4 The summary of results from the logistic regression models

\begin{tabular}{|c|c|c|c|c|c|c|c|c|}
\hline \multirow{3}{*}{$\begin{array}{l}\text { Baseline factors } \\
\text { Age }\end{array}$} & \multicolumn{4}{|c|}{ Being advised to attend the second session } & \multicolumn{4}{|c|}{ Attending multiple sessions } \\
\hline & \multirow{2}{*}{$\begin{array}{c}\text { OR } \\
1.01\end{array}$} & \multicolumn{2}{|c|}{$95 \% \mathrm{Cl}$} & \multirow{2}{*}{$\begin{array}{c}p \text { value } \\
0.04\end{array}$} & \multirow{2}{*}{$\begin{array}{c}\text { OR } \\
1.03\end{array}$} & \multicolumn{2}{|c|}{$95 \% \mathrm{Cl}$} & \multirow{2}{*}{$\begin{array}{c}p \text { value } \\
<0.01\end{array}$} \\
\hline & & 1.00 & 1.01 & & & 1.03 & 1.04 & \\
\hline BMl & 1.00 & 0.99 & 1.02 & 0.44 & 1.00 & 1.00 & 1.01 & 0.78 \\
\hline SBP & 1.02 & 1.01 & 1.02 & $<0.01$ & 1.00 & 1.00 & 1.00 & 0.02 \\
\hline DBP & 1.01 & 1.00 & 1.01 & 0.04 & 1.00 & 1.00 & 1.00 & 0.11 \\
\hline \multicolumn{9}{|l|}{ Gender } \\
\hline Male $^{1}$ & 1.11 & 1.00 & 1.23 & 0.06 & 1.00 & 0.91 & 1.11 & 0.98 \\
\hline \multicolumn{9}{|l|}{ Previous TIA? } \\
\hline Yes $^{2}$ & 0.96 & 0.78 & 1.20 & 0.74 & 0.94 & 0.79 & 1.11 & 0.91 \\
\hline \multicolumn{9}{|l|}{ Previous stroke? } \\
\hline Yes $^{2}$ & 1.01 & 0.72 & 1.41 & 0.97 & 1.07 & 0.83 & 1.38 & 0.55 \\
\hline \multicolumn{9}{|c|}{ Previous heart attack? } \\
\hline $\mathrm{Yes}^{2}$ & 1.12 & 0.95 & 1.33 & 0.17 & 0.89 & 0.76 & 1.03 & 0.27 \\
\hline \multicolumn{9}{|l|}{ High cholesterol? } \\
\hline Yes $^{2}$ & 1.05 & 0.94 & 1.17 & 0.36 & 1.01 & 0.93 & 1.10 & 0.31 \\
\hline \multicolumn{9}{|l|}{ Diabetes? } \\
\hline Yes $^{2}$ & 1.11 & 0.95 & 1.29 & 0.18 & 0.96 & 0.85 & 1.08 & 0.46 \\
\hline \multicolumn{9}{|l|}{ Hypertension? } \\
\hline$Y_{e s}^{2}$ & 1.19 & 0.98 & 1.44 & 0.07 & 1.30 & 1.19 & 1.42 & 0.01 \\
\hline \multicolumn{9}{|l|}{ Currently smoking? } \\
\hline Yes $^{2}$ & 1.01 & 0.85 & 1.20 & 0.89 & 0.87 & 0.75 & 1.01 & 0.06 \\
\hline \multicolumn{9}{|c|}{ How many times eating high fat food in a week? } \\
\hline Zero $^{3}$ & 0.93 & 0.76 & 1.14 & 0.48 & 0.90 & 0.77 & 1.06 & 0.22 \\
\hline $1-2$ times $^{3}$ & 0.95 & 0.79 & 1.14 & 0.58 & 0.97 & 0.83 & 1.12 & 0.63 \\
\hline \multicolumn{9}{|c|}{ Two or more alcoholic drinks a day? } \\
\hline Yes $^{2}$ & 0.92 & 0.77 & 1.09 & 0.34 & 0.94 & 0.80 & 1.10 & 0.26 \\
\hline \multicolumn{9}{|c|}{ At least five servings of fruits and vegetables daily? } \\
\hline Yes $^{2}$ & 1.10 & 0.98 & 1.22 & 0.10 & 1.14 & 1.04 & 1.24 & 0.01 \\
\hline \multicolumn{9}{|c|}{ Adding salt to food? } \\
\hline Rarely $^{4}$ & 1.06 & 0.92 & 1.23 & 0.43 & 1.18 & 1.03 & 1.34 & 0.02 \\
\hline Sometimes $^{4}$ & 1.08 & 0.93 & 1.27 & 0.31 & 1.16 & 1.00 & 1.34 & 0.05 \\
\hline \multicolumn{9}{|l|}{ Feeling stressed? } \\
\hline Rarely ${ }^{4}$ & 0.84 & 0.73 & 0.98 & 0.02 & 1.04 & 0.92 & 1.19 & 0.98 \\
\hline Sometimes $^{4}$ & 0.80 & 0.69 & 0.92 & $<0.01$ & 1.06 & 0.93 & 1.21 & 0.79 \\
\hline \multicolumn{9}{|c|}{ Daily exercise for 30 to 60 minutes most days } \\
\hline Yes $^{2}$ & 0.97 & 0.86 & 1.10 & 0.64 & 1.05 & 0.94 & 1.16 & 0.19 \\
\hline \multicolumn{9}{|l|}{ Live alone? } \\
\hline Yes $^{2}$ & 1.16 & 1.04 & 1.29 & 0.01 & 1.17 & 1.06 & 1.28 & $<0.01$ \\
\hline
\end{tabular}

$\mathrm{BMI}=$ body mass index; $\mathrm{SBP}=$ systolic blood pressure; $\mathrm{DBP}=$ diastolic blood pressure; $\mathrm{TI} \mathrm{A}=$ transient ischemic attack; $\mathrm{OR}=$ odds ratio; $\mathrm{Cl}=$ confidence interval. ${ }^{1}$ Compared with female as reference category.

${ }^{2}$ Compared with 'no' as reference category.

${ }^{3}$ Compared with ' 3 or more' as reference category.

${ }^{4}$ Compared with 'often' as reference category.

Significant $p$ values $(\leq 0.05)$ were bolded. 
health within communities. Third, we showed that CHAP was effective in reducing BP in the elderly residing in midsized Ontario communities. These findings may not be generalizable to larger communities or urban centers where healthcare is delivered differently [22]. Fourth, CHAP was explicitly designed to target the older adults who are at least 65 years old. Thus, our findings may not hold for younger people. Fifth, the participation in CHAP was on a self-directed basis and the attrition was significant. The majority of participants attended no more than two sessions and were excluded from the longitudinal analysis of BP reduction over time. We were not able to follow those participants for their cardiovascular condition and lifestyle change at various months of the study although the baseline comparison showed that the participants with fewer visits had lower cardiovascular risk and a less healthy lifestyle. Finally, the estimates of BP reductions were derived for the population average rather than individual participants. Limited by the design, we did not protect the study from regression to the mean (RTM) bias by randomly allocating the CHAP intervention to the participants who had high BP at baseline and those who did not. However, we tried to reduce the RTM bias by recording the average BP in each measurement. We also accounted for the participants' baseline BP when estimating the BP change. Both approaches were suggested by Barnett et al. to deal with MTR bias [42]. Using the standard formula [42], we calculated the effect of RTM in our sample to be approximately 2.0 and $0.6 \mathrm{mmHg}$ for SBP and DBP, respectively. Both numbers imply a weak effect of RTM in the participants' mean SBP and DBP.

Despite the limitations, this study has several important strengths. The CHAP intervention is evaluated by largescale population-based data that enables longer follow-up and larger sample size. Data are rarely available for evaluation of a real-world program at this scale. The continuous and accurate monitoring of blood pressure in a familiar environment allows for a better level of diagnosis, treatment, and control of hypertension. Among the CHAP participants initially identified with elevated BP, 33\% of them did not report hypertension, suggesting that these individuals might not be aware of their condition. Moreover, $11 \%$ of the participants diagnosed with hypertension previously were not receiving antihypertensive medication. When we explored the group of participants who showed high $\mathrm{BP}$ at baseline, we did not find any significant difference in the BP change between the ones who reported hypertension and those who did not. On average, the ones who did not report hypertension had only $0.11 \%(\mathrm{p}=0.39)$ and $0.17 \%(p=0.15)$ more reduction per month in SBP and DBP, respectively, than those who did. Traditional system barriers associated with a clinical setting are overcome by the use of community pharmacies and volunteer peer health educators who are closely related to their peers. A system such as this also helps to enhance participant adherence to recommended lifestyle changes and pharmacologic treatments.

Some well-known community-wide interventions for CVD [11-13,28,29] have failed to detect significant changes in CVD risk factors or have shown only modest improvements in BP. Those studies were largely limited by small size, short duration, narrow penetration of the intervention, and a focus shifted from awareness and prevention $[43,44]$. In addition to overcoming those limitations, CHAP adopts a community-led, collaborative approach to primary health care and cardiovascular health awareness. It removes traditional barriers to monitoring and management of blood pressure [45]. Unlike other community BP monitoring initiatives, CHAP ensures that accurate and up-to-date information is forwarded to participants' family physician and pharmacist [46]. The ACHAMP in Alberta [19], a community BP program built on the CHAP model, also showed a significant $\mathrm{BP}$ reduction after a 6-month follow-up.

Hypertension among the modifiable risk factors of CVD represents a major public health issue and its suboptimal detection and treatment is a major burden on health care expenditures and significant CVD morbidity and mortality for those who are not adequately controlled [22]. CHAP offers a feasible, community-based, and affordable means to improve the BP management. Considering that $36 \%$ of Canadians aged 65 to 74 are uncontrolled [8], CHAP appears to present a significant step forward in the prevention of cardiovascular disease through monitoring individuals' BP.

\section{Conclusions}

Hypertension is highly preventable and manageable through lifestyle changes and pharmacological treatments. Our study showed that the CHAP participants initially identified with high BP experienced a significant reduction of BP during repetitive visits. Participants who presented with higher risks of developing cardiovascular diseases were more likely to attend multiple sessions. CHAP integrates community resources to promote cardiovascular health awareness and prevention among older adults to improve the diagnosis, treatment, and control of blood pressure, thus decreasing the risk of developing cardiovascular disease.

\section{Additional file}

Additional file 1: Specifics of the Bivariate Model.

\section{Abbreviations}

CVD: Cardiovascular disease; CHAP: Cardiovascular health awareness program; SBP: Systolic blood pressure; DBP: Diastolic blood pressure;

BP: Blood pressure; CAR: Continuous autoregressive; MAR: Missing at random; MI: Multiple imputation; MCMC: Monte Carlo Markov Chain; RR: Rate ratio;

$\mathrm{Cl}$ : Confidence interval; BMI: Body mass index; RTM: Regression to the mean. 


\section{Competing interests}

The authors declare that they have no competing interests.

\section{Authors' contributions}

CY and LD conceived the research question; CY proposed the statistical methods, performed all analyses, interpreted the results, and drafted and revised the manuscript; JK, LWC and LD led the implementation of the CHAP study, advised on the interpretation of results and revised the manuscript; GF and LT contributed to the statistical analyses and revision of the manuscript; RA, FM and SL contributed to the implementation of the study and revision of the manuscripts; All authors have read and approved the final manuscript.

\section{Acknowledgements}

Chenglin Ye is supported in part by funding from the Father Sean O'Sullivan Research Center (FSORC) Studentship award, the Canadian Institute of Health Research (ClHR) Training award in Bridging Scientific Domains for Drug Safety and Effectiveness, and the Canadian Network and Centre for Trials Internationally (CANNeCTIN) programme.

\section{Author details}

${ }^{1}$ Department of Clinical Epidemiology and Biostatistics, McMaster University, Hamilton, ON, Canada. 'Biostatistics Unit, St. Joseph's Healthcare Hamilton, Hamilton, ON, Canada. ${ }^{3}$ Department of Family Medicine, McMaster University, McMaster Innovation Park, 175 Longwood Road South, Hamilton, ON L8P OA1, Canada. ${ }^{4} \mathrm{CRCHUM}$ and Département de médecine de famille et de médecine d'urgence, Université de Montréal, Montreal, Canada. ${ }^{5}$ Institut de recherche Élisabeth-Bruyère Research Institute, Bruyère Continuing Care and University of Ottawa, Ottawa, ON, Canada. ${ }^{6}$ Institute for Clinical Evaluative Sciences, Toronto, ON, Canada. ${ }^{7}$ Faculty of Health, York University, Toronto, ON, Canada. ${ }^{8}$ Pan-American Health Organization / World Health Organization, Paramaribo, Suriname.

Received: 15 August 2013 Accepted: 17 December 2013 Published: 25 December 2013

\section{References}

1. Heart and Stroke Foundation of Canada: The Growing Burden of Heart Disease and Stroke in Canada. http://www.cvdinfobase.ca/cvdbook/ CVD_En03.pdf; last date of access: 2013 Mar 26.

2. Cardiovascular Health Services in Ontario. In An ICES Atlas. Edited by Naylor CD, Slaughter PM. Toronto, ON: Institute for Clinical Evaluative Sciences; 1999:1-11.

3. Lim SS, Vos T, Flaxman AD, et al: A comparative risk assessment of burden of disease and injury attributable to 67 risk factors and risk factor clusters in 21 regions, 1990-2010: a systematic analysis for the Global Burden of Disease Study 2010. Lancet 2012, 380(9859):2224-2260.

4. Wolf-Maier K, Cooper RS, Banegas JR, et al: Hypertension prevalence and blood pressure levels in 6 European countries, Canada and the United States. JAMA 2003, 289:2363-2369.

5. Burt VL, Whelton P, Roccella EJ, et al: Prevalence of hypertension in the US adult population. Results from the third national health and nutrition examination survey, 1988-1991. Hypertension 1995, 25:305-313.

6. Joffres MR, Hamet P, Rabkin SW, et al: Prevalence, control and awareness of high blood pressure among Canadian adults. Canadian heart health surveys research group. CMAJ 1992, 146:1997-2005.

7. Vasan RS, Beiser A, Seshadri S, et al: Residual lifetime risk for developing hypertension in middle-aged women and men: the Framingham heart study. JAMA 2002, 287:1003-1010.

8. McAlister FA, Wilkins K, Joffres M, et al: Changes in the rates of awareness, treatment and control of hypertension in Canada over the past two decades. CMAJ 2011, 183(9):1007-1013.

9. Parati G, Mancia G: White coat effect: semantics, assessment and pathophysiological implications. J Hypertens 2003, 21(3):481-486.

10. Bobrie G, Chatellier G, Genes N, et al: Cardiovascular prognosis of "masked hypertension" detected by blood pressure self-measurement in elderly treated hypertensive patients. JAMA 2004, 291(11):1342-1349.

11. Farquhar JW, Fortmann SP, Flora JA, et al: Effects of communitywide education on cardiovascular disease risk factors. The Stanford Five-City Project. JAMA 1990, 264(3):359-365.
12. Luepker RV, Rastam L, Hannan PJ, et al: Community education for cardiovascular disease prevention. Morbidity and mortality results from the Minnesota Heart Health Program. Am J Epidemiol 1996, 144(4):351-362.

13. Carleton RA, Lasater TM, Assaf AR, et al: The Pawtucket Heart Health Program: community changes in cardiovascular risk factors and projected disease risk. Am J Public Health 1995, 85(6):777-785.

14. Düsing R: Overcoming barriers to effective blood pressure control in patients with hypertension. Curr Med Res Opin 2006, 22(8):1545-1553.

15. Neuhouser ML, Miller DL, Kristal AR, et al: Diet and exercise habits of patients with diabetes, dyslipidemia, cardiovascular disease or hypertension. J Am Coll Nutr 2002, 21(5):394-401.

16. Salzman C: Medication compliance in the elderly. J Clin Psychiatry 1995, 56(Suppl 1):18-22.

17. Serour M, Alqhenaei $\mathrm{H}, \mathrm{Al}$-Saqabi S, et al: Cultural factors and patients' adherence to lifestyle measures. Br J Gen Pract 2007, 57(537):291-295.

18. Klawansky S: Treatment of hypertension. In Medicine Worth Paying for: Assessing Medical Innovations. Edited by Frazier HS, Mosteller F. Cambridge: Harvard University Press; 1995:139-154.

19. Jones C, Simpson SH, Mitchell D, et al: Enhancing hypertension awareness and management in the elderly: lessons learned from the Airdrie Community Hypertension Awareness and Management Program (A-CHAMP). Can J Cardiol 2008, 24(7):561-567.

20. Chabot I, Moisan J, Grégoire JP, et al: Pharmacist intervention program for control of hypertension. Ann Pharmacother 2003, 37:1186-1193.

21. Zillich AJ, Sutherland JM, Kumbera PA, et al: Hypertension outcomes through blood pressure monitoring and evaluation by pharmacists (HOME Study). J Gen Intern Med 2005, 20:1091-1096.

22. Kaczorowski J, Chambers LW, Dolovich L: Improving cardiovascular health at population level: 39 community cluster randomized trial of Cardiovascular Health Awareness Program (CHAP). BMJ 2011, 342:d442.

23. Laverack G: Improving health outcomes through community empowerment: a review of the literature. J Health Popul Nutr 2006, 24(1):113-120.

24. Chambers LW, Kaczorowski J, Dolovich L, et al: A Community-based Program for Cardiovascular Health Awareness. Can J Publ Health 2005, 96(4):294-298.

25. Chambers LW, Kaczorowski J, Levitt C, et al: Blood pressure self-monitoring in pharmacies. Building on existing resources. Can Fam Physician 2002, 48:1594-1595

26. CHAP Working Group: CHAP: A community approach to better cardiovascular health. http://www.chapprogram.ca. Last date of access: 2013 Mar 26.

27. Karwalajtys T, Kaczorowski J, Chambers LW, et al: A randomized trial of mail vs. telephone invitation to a community-based cardiovascular health awareness program for older family practice patients. BMC Fam Pract 2005, 19:35.

28. Puska P, Salonen JT, Nissinen A, et al: Change in risk factors for coronary heart disease during 10 years of a community intervention programme (North Karelia project). BMJ 1983, 287(6408):1840-1844.

29. Record NB, Harris DE, Record SS, et al: Mortality impact of an integrated community cardiovascular health program. Am J Prev Med 2000, 19(1):30-38.

30. Kaczorowski J, Chambers LW, Karwalajtys T, et al: Cardiovascular Health Awareness Program (CHAP): A community cluster-randomised trial among elderly Canadian. Prev Med 2008, 46:537-544.

31. Singer J, Willett JB: Applied longitudinal data analysis: modeling change and event occurrence. New York: Oxford University Press; 2003.

32. Funatogawa I, Funatogawa T, Ohashi Y: A bivariate autoregressive linear mixed effects model for the analysis of longitudinal data. Statist Med 2008, 27:6367-6378.

33. Fieuws $\mathrm{S}$, Verbeke G: Joint modelling of multivariate longitudinal profiles: pitfalls of the random-ffects approach. Stat Med 2004, 23:3093-3104.

34. Thiebaut $R$, Jacqmin-Gadda H, Chene $G$, et al: Bivariate linear mixed models using SAS proc MIXED. Comput Meth Programs Biomed 2002, 69(3):249-256

35. Potthoff RF, Roy SN: A generalized multivariate analysis of variance model useful especially for growth curve problems. Biometrika 1964, 51(3-4):313-326

36. Jones $\mathrm{RH}$, Ackerson LM: Serial correlation in unequally spaced longitudinal data. Biometrika 1990, 77(4):721-731.

37. Jones $\mathrm{RH}$, Boadi-Boateng F: Unequally spaced longitudinal data with AR (1) serial correlation. Biometrics 1991, 47:161-175. 
38. Nunez-Anton V, Woodworth GG: Analysis of longitudinal data with unequally spaced observations and time-dependent correlated errors. Biometrics 1994, 50:445-456.

39. Daskalopoulou SS, Khan NA, Quinn RR, et al: The 2012 Canadian hypertension education program recommendations for the management of hypertension: blood pressure measurement, diagnosis, assessment of risk, and therapy. Can J Cardiol 2013, 28(3):270-287.

40. Kiernan K, Tao J, Gibbs P: Tips and Strategies for Mixed Modeling with SAS/STAT ${ }^{\oplus}$ Procedures. SAS Global Forum 2012:332-2012. http://support.sas. com/resources/papers/proceedings12/332-2012.pdf; last date of access: 2013 Mar 26.

41. Hypertension Canada. https://www.hypertension.ca/what-is-hypertensiondp1; last data of access: 2013 Mar 26.

42. Barnett $A G$, van der Pols JC, Dobson AJ: Regression to the mean: what it is and how to deal with it. Int J Epidemiol 2005, 34:215-220.

43. Pennant M, Davenport C, Bayliss $\mathrm{S}$, et al: Community programs for the prevention of cardiovascular disease: a systematic review. Am J Epidemiol 2010, 172:501-516.

44. Parker DR, Assaf AR: Community interventions for cardiovascular disease. Prim Care 2005, 32:865-881.

45. Campbell NR, Jeffrey P, Kiss K, et al: Building capacity for awareness and risk factor identification in the community: the blood pressure assessment program of the Calgary fire department. Can J Cardiol 2001, 17(12):1275-1279.

46. Chambers LW, Kaczorowski J, O'Rielly S, et al: Comparison of blood pressure measurement using an automated blood pressure device in community pharmacies and physicians? Offices: The collingwoodcreemore randomized controlled trial. CMAJ Open 2013. in press.

doi:10.1186/1471-2458-13-1230

Cite this article as: Ye et al:: The impact of a cardiovascular health awareness program (CHAP) on reducing blood pressure: a prospective cohort study. BMC Public Health 2013 13:1230.

\section{Submit your next manuscript to BioMed Central and take full advantage of:}

- Convenient online submission

- Thorough peer review

- No space constraints or color figure charges

- Immediate publication on acceptance

- Inclusion in PubMed, CAS, Scopus and Google Scholar

- Research which is freely available for redistribution 